\title{
ПРАКТИЧЕСКИЕ РЕКОМЕНДАЦИИ ПО ЛЕЧЕНИЮ СИНДРОМА АНОРЕКСИИ-КАХЕКСИИ У ОНКОЛОГИЧЕСКИХ БОЛЬНЫХ
}

Коллектив авторов: Сытов А.В., Зузов С.А., Лейдерман И.Н., Хотеев А.Ж. DOI: $10.18027 / 2224-5057-2020-10-3 s 2-44$

Ключевые слова: кахексия, анорексия

Кахексия в контексте онкологической патологии представляет собой сложный метаболический синдром, обусловленный опухолевым заболеванием и характеризующийся потерей мышечной массы в сочетании или без потери жировой ткани. С кахексией часто связаны анорексия, воспаление, инсулинорезистентность и повышенный распад мышечного белка. Кахексия у онкологического больного отличается от простого голодания, возрастной потери мышечной массы, первичной депрессии, нарушения всасывания и гипертиреоза, и связана с прогрессированием опухолевого процесса. Большое количество наблюдений указывает на роль полипептидов, выделяемых, в основном, иммунными клетками, цитокинов, инициирующих различные метаболические изменения, связанные, прежде всего с гиперметаболизмом, который характерен для онкологического процесса. Эта воспалительная реакция может играть центральную роль в патогенезе развития кахексии, однако, не следует забывать о многофакторности этиологии кахексии. Несколько исследований, посвящённых механизмам, лежащим в основе обмена веществ и изменения состава тканей, наблюдаемых при кахексии у онкологических пациентов, выявили потенциально важную роль опухоль-ассоциированных субстанций, индуцирующих развитие кахексии, мишенью которых, как представляется, являются скелетные мышцы. В частности, одной из причин деградации белков при кахексии у онкологического больного может быть убиквитин-протеасомный путь.

Анорексия, т. е. отсутствие аппетита, часто наблюдается у пациентов со многими видами заболеваний на поздней стадии (например, сердечная недостаточность, рак, хроническая почечная недостаточность, хроническая обструктивная болезнь лёгких). Анорексия, возникающая в условиях онкологического заболевания, может являться важной адаптивной реакцией, позволяющей организму мобилизовать энергетические ресурсы для поддержания метаболизма, необходимого для адекватного иммунного ответа и минимизации повреждений, связанных с основным процессом. Отсутствие

Цитирование: Сытов А.В., Зузов С.А., Лейдерман И.Н., Хотеев А.Ж. Практические рекомендации по лечению синдрома анорексии-кахексии у онкологических больных. Злокачественные опухоли: Практические рекомендации RUSSCO \#3s2, 2020 (том 10).44 
аппетита может быть также следствием специфического лечения, изменения вкусовых ощущений, сухости во рту, тошноты, нарушения моторики ЖКТ, включая гастропарез и запор, хронической усталости, депрессии, боли, что способствует развитию анорексии. Эти симптомы называются «вторичными симптомами воздействия на питание».

В связи с тесной взаимосвязью кахексии и анорексии в 2000-х гг. было сформировано понятие «синдром анорексии-кахексии онкологических больных» (САКОБ).

\section{1. ДИАГНОСТИКА}

Все пациенты с подозрением на САКОБ должны быть обследованы с целью выяснения состояния питания и степени потери веса. Клиническая оценка включает в себя тщательный сбор анамнеза, ориентированный на вопросы питания, выяснение факторов риска, приводящих к развитию нутритивной недостаточности, а также физикальное обследование с акцентом на диагностику состояния жировой и мышечной массы (височная область, дельтовидные и четырёхглавые мышцы), оценку тонуса мышц при пальпации, наличие периферических отёков или асцита. Наиболее часто используемыми объективными показателями состояния питания являются измерение массы тела и оценка пищевого рациона. Лабораторные показатели состояния питания (например, альбумин, трансферрин) редко необходимы для оценки пищевого статуса, хотя некоторые инструменты скрининга включают измерение сывороточного альбумина. Для установления диагноза кахексии необходимы пять составляющих:

- истощение запасов мышечной массы и силы;

- анорексия или уменьшение потребления пищи;

- наличие катаболических маркёров;

- функциональные нарушения;

- психосоциальные последствия.

Чётких рекомендаций относительно алгоритма диагностики САКОБ не существует.

\section{2. ОПРЕДЕЛЕНИЕ СТАДИИ КАХЕКСИИ}

Международная группа исследователей разработала систему определения стадии кахексии у онкологических больных:

- прекахексия:

- потеря массы тела на $\leq 5 \%$ за последние 6 мес.;

- признаки системного воспалительного ответа;

- анорексия и метаболические изменения; 
- кахексия:

- потеря массы тела на > 5\% за последние 6 мес. (при условии, что пациент не голодал специально) или

- продолжающаяся потеря массы тела более, чем на 2\%, индекс массы тела менее 20 кг/ $^{2}$ или

- потеря скелетной мускулатуры и продолжающаяся потеря массы тела более $2 \%$;

- признаки системного воспалительного ответа, анорексия, снижение потребления объёма пищи;

- рефрактерная кахексия: критерии кахексии на фоне выраженного катаболизма, отсутствие эффекта противоопухолевой терапии, ECOG 3-4, ожидаемая продолжительность жизни менее 3 мес.

\section{3. ЛЕЧЕНИЕ}

\subsection{0бщие аспекты}

Потеря аппетита и изменение внешности вследствие кахексии представляют собой крайне тревожные симптомы, как для пациентов, так и для членов семьи. Пациентам с САКОБ, которые в состоянии принимать пищу, следует рекомендовать частые приёмы небольших количеств высококалорийной пищи (например, яйца, жидкие пищевые добавки). Для улучшения питания следует выбирать блюда, которые требуют меньших усилий при приготовлении (например, в микроволновой печи). Несмотря на положительный эффект от применения пищевых добавок, пациенты и члены семьи должны знать, что увеличение потребления калорий не сможет остановить основной процесс, а анорексия и кахексия отличаются от голодной смерти и являются нередкими симптомами онкологических заболеваний, закономерно развивающимися в конце жизни онкологического больного. Оптимизация лечения основных причин анорексии - тошноты, запора, изменений вкуса, одышки, депрессии, может привести к значительному улучшению состояния. Для пациентов с персистирующей анорексией оптимальными являются фармакологические методы лечения, преимущественно направленные на стимуляцию аппетита. В многочисленных исследованиях было продемонстрировано улучшение аппетита и/или увеличение веса у отдельных пациентов с САКОБ, однако данная терапия не обращает вспять кахексию и не улучшает выживаемость и качество жизни.

\section{2. Фармакологическая терапия}

Для стимуляции аппетита могут использоваться прогестагены и ГКС. 


\subsection{1. Лечение с доказанной клинической эффективностью}

\subsubsection{1. Прогестагены (мегестрола ацетат)}

Мегестрола ацетат является синтетическим прогестагеном. При САКОБ мегестрола ацетат благотворно влияет на аппетит и общий вес. Однако это никак не влияет на качество жизни или увеличение мышечной массы тела. Чтобы свести к минимуму неблагоприятные последствия, рекомендуется начинать приём с низкой дозы (160 мг/сут.) и увеличивать её до максимума (800 мг/сут.).

\subsubsection{2. Глюкокортикостероиды}

ГКС хорошо известны как препараты, стимулирующие аппетит у онкологических больных. На сегодняшний день нет чётких рекомендаций касательно оптимальных доз и продолжительности лечения ГКС. Большинство исследователей применяли преднизолон 20-40 мг/сут. или дексаметазон в эквивалентных дозах (3-4 мг/сут.) на протяжении 2-4 недель. Вопросы коррекции симптомов анорексии с помощьюГКС требуют дополнительных исследований.

\subsection{2. Лечение гастропареза}

Гастропарез и раннее насыщение успешно устраняют с помощью коррекции диеты, например, путём частого дробного (небольшими порциями) приёма пищи в течение дня, а также назначением прокинетиков, таких как метоклопрамид и эритромицин, реже - цизаприд и домперидон.

Применение ципрогептадина показано пациентам с карциноидным синдромом, у которых есть признаки САКОБ. В этой ситуации ципрогептадин, по-видимому, действует путём прямого противодействия увеличению активности серотонина. В соответствующих клинических исследованиях ципрогептадин в дозе 8 мг 3 раза в день оказывал мягкое стимулирующее действие на аппетит, но не приводил к увеличению веса. При других нозологических формах его эффективность не была доказана.

\subsection{3. Препараты, находящиеся в стадии изучения}

Среди изучаемых препаратов стоит отметить омега- 3 жирные кислоты, НПВС (селективные ингибиторы циклооксигеназы- 2), талидомид, миртазапин/оланзапин, грелин, аминокислоты, L-карнитин. Роль комбинированной терапии при лечения САКОБ остаётся неясной. Нет доказательств того, что какая-либо комбинация препаратов является безопасной и более эффективной, чем однокомпонентная терапия с использованием, например, ГКС или аналогов прогестерона. 